\title{
Coral larval settlement and post-settlement survival facilitated by crustose coralline algae with or without living tissue
}

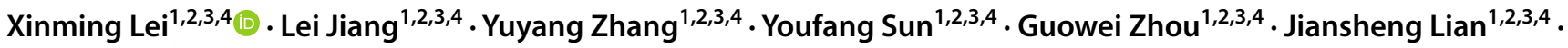 \\ Hui Huang ${ }^{1,2,3,4}$
}

Received: 4 November 2020 / Accepted: 7 July 2021 / Published online: 24 July 2021

(c) The Author(s) 2021

\begin{abstract}
Selection of a permanent attachment site of coral larvae can be a critical determinant of recruitment success affecting the structure of coral communities and underpins the ability of coral reef ecosystems to recover from disturbance. Settlement specificity of a threatened coral in Sanya reefs, Acropora millepora, was tested by measuring the larval metamorphosis preferences and post-settlement survival in response to crustose coralline algae (CCA) species Hydrolithon reinboldii and other substrata. In the no-choice experiments, the larvae of A. millepora had similar rates of total metamorphosis with the presence of CCA regardless of the algae tissue being alive or not, and settlement success induced by CCA was higher than by other substrata (tile or glass). In the paired-choice experiments, when CCA was in presence, the coral larvae preferred the surface of the dish and the side of living CCA. In the absence of CCA, total larvae metamorphosis was lower than in the treatments where CCA was present. New recruits of A. millepora had approximately $68 \%$ mean survival on all the settlement substrata after 2 weeks maintained in aquaria with flow-through seawater similar to the coral larval sampling site, but with no coral spat survival in the treatments where CCA was absent. However, there were statistical differences between the larvae survival of dead CCA and glass chips treatment and the others where CCA was present. Our results were consistent with the conclusion that some CCA species could facilitate coral larval settlement and post-settlement survivorship, highlighting the importance of substrata selection success for facilitating coral recruitment in the threatened coral reefs.
\end{abstract}

Responsible Editor: S. Harii.

Reviewed by: undisclosed experts.

Hui Huang

huanghui@scsio.ac.cn

1 CAS Key Laboratory of Tropical Marine Bio-resources and Ecology, South China Sea Institute of Oceanology, Chinese Academy of Sciences, Guangzhou 510301, China

2 Guangdong Provincial Key Laboratory of Applied Marine Biology, South China Sea Institute of Oceanology, Chinese Academy of Sciences, Guangzhou 510301, China

3 Innovation Academy of South China Sea Ecology and Environmental Engineering, Chinese Academy of Sciences, Guangzhou 510301, China

4 CAS-HKUST Sanya Joint Laboratory of Marine Science Research and Key Laboratory of Tropical Marine Biotechnology of Hainan Province, Tropical Marine Biological Research Station in Hainan, Chinese Academy of Sciences, Sanya 572000, China

\section{Introduction}

Coral reefs are facing intensifying threats worldwide, largely due to chronic and acute environmental variability or anthropogenic disturbers. Multiple positive and negative factors can influence coral recovery and community dynamics (Pearson 1981, Knowlton 2001, Sato et al. 2018). Coral larval recruitment is a crucial ecological process that affects the structure and maintenance of reef communities (Price 2010, Ritson-Williams et al. 2010, Price et al. 2019).Therefore, the successful settlement and recruitment of larvae to the optimal substrata is a vital step in the process of population recovering from a decimated coral reef (Pearson 1981, Polidoro and Carpenter 2013, Kayal et al. 2018). It is well documented that corals have an array of life history and larval strategies, hinting there maybe species-specific habitat selection for successful recruitment.

Several laboratory studies suggest that numerous coral larvae preferred to select particular species of crustose coralline algae (CCA) as their settlement substrate (Harrington et al. 2004, Ritson-Williams et al. 2010, 2016, 
Tebben et al. 2015, Gomez-Lemos et al. 2018, Siboni et al. 2020). Some coral larvae settle and metamorphose in response to the microbiological (epiphytic microbial biofilm) (Webster et al. 2004, Sneed et al. 2014) and chemical (Sneed et al. 2014, Tebben et al. 2015) cues of CCA. Coral larvae are capable of sensing these inducing cues to explore suitable settlement substrate (Tran and Hadfield 2013). But not all species of CCA facilitate larval settlement and some studies show CCA is not required for coral larval settlement (Ritson-Williams et al. 2010). In addition, some CCA species have mechanisms that inhibit the settlement of coral larvae (Harrington et al. 2004). Study reported some coral larvae may use spectral cues for fine-scale habitat selection during settlement (Mason et al. 2011). Research found the morphological characteristics of dead coral substratum had a significant influence on the coral recruitment patterns with respect to the morphology of the recruits (Norstrom et al. 2007), and some corals prefer recruiting onto live or dead shells (Laju et al. 2019). Additionally, (Whalan et al. 2015) suggested specific physical cues (surface microtopography alone without chemical cues) also play an important contributing role in the settlement of coral larvae. Hence, despite the advances in previous research of the role of CCA as inducers of coral larval settlement, it remains unclear whether coral settlement is mediated by CCA itself or other related inducers (Randall et al. 2020). Moreover, the inducing cues involved in the inherent feature of CCA had been overlooked in some extent.

Acropora millepora used to be a dominant corymbose (branching) scleractinian coral throughout the Sanya coral reef in shallow water habitats before 2001 (Yu and Zhou 1996, Lian et al. 2010); however, due to terrestrial inputs and human activities, such as over-fishing, diving tourism and dredged sediment (Hutchings and Wu 1987, Fiege et al. 1994, Li et al. 2013), it can be only found sporadically in recent years (Sun et al. 2018). A. millepora is a type of hermaphroditic spawner that release its gametes into the water column for external fertilization (Zhang et al. 2016) and important structural components of shallow Sanya reefs (Yu and Zhou 1996). Nevertheless, little research had documented on the larval ecology of the species in this area.

To better understand the substrate characteristics that facilitate larval settlement of a threatened coral species, Acropora millepora, in Sanya reefs, we conducted a series of manipulative laboratory experiments to elucidate the efficiency by a CCA (Hydrolithon reinboldii) and other substrate inducing the settlement of coral larvae in the Sanya Reefs, Southern China. After the settlement experiments, substrata chips with newly metamorphosed coral spat were used to compare post-settlement survival. Here, we subjected coral larvae to a multi-choice experiment, documenting different strategies in settlement preference and post-settlement survival among coral larvae.

\section{Materials and methods}

\section{Study site and species}

The experiments were conducted at the Tropical Marine Biological Research Station in Hainan $\left(109^{\circ} 28^{\prime}\right.$ E, $18^{\circ} 13^{\prime}$ $\mathrm{N}$ ), southern China. It is located at Sanya Bay, and characterized as a tropical habitat with abundant of reef-associate organisms in shallow water ( $<6 \mathrm{~m}$ depth). The corals $(A$. millepora) were monitored in situ at night, and when spawning occurred, the gamete bundles from 3 to 6 colonies were collected with nylon nets, then mixed in a $15 \mathrm{~L}$ bucket and gently agitated to facilitate bundle disintegration and crossfertilization (May 7th, 2016), and maintained in the laboratory following methods described by Ritson-Williams et al. (2010). Larvae of A. millepora were raised in flowing filtered seawater (FSW), and they were used 5 days after fertilization for the designed experiments, according to the previous studies on the peak settlement period of mass-spawning of Acropora (Nozawa and Harrison 2008, Suzuki et al. 2011).

A crustose coralline algae (CCA) species, Hydrolithon reinboldii was used as one of the coral larval settlement substrates in the experiments. This CCA species is common and widely distributed in shallow benthic habitats $(<6 \mathrm{~m}$ depth) in the sampling area (Lei et al. 2018). To assess larval settlement, $H$. reinboldii with living and dead tissue, tiles made from terracotta, and glass slides were employed in the experiments. CCA species were collected at 2-3 m depths in Luhuitou fringing reef and cut into uniformly sized chips $(0.5 \times 0.5 \times 0.3 \mathrm{~cm})$ raised in flowing seawater for two weeks until being used in a settlement experiments. A few of the CCA chips were dried in the air for $48 \mathrm{~h}$ and keep them in a desiccator to produce test materials for the "dead CCA" treatments. The tiles and glass slides were cut into the similar size as the CCA chips and had been pre-conditioned in running FSW for 1 month prior to the experiments, and then the surface was cleaned with freshwater by a brush before utilizing.

\section{Larval settlement and post-settlement survival experiments}

For each replicate, 20 active larvae (5 days old) were placed in $15 \mathrm{ml} \mathrm{FSW}$ in a $5.5 \mathrm{~cm}$ diameter plastic petri dish, and then they were kept in the air-conditioned room to ensure temperature constant $\left(27 \pm 0.5{ }^{\circ} \mathrm{C}\right)$. The temperature reflected the monthly mean temperature at the site from which coral larvae were collected. Petri dishes with $15 \mathrm{ml}$ FSW were used as experimental control. Five replicate 
dishes for each treatment were set up simultaneously with a single piece of test chips in each no-choice experiment and two of each chips in every paired-choice experiment. Experimental dishes were arranged in a randomized block design. We did not aerate the experimental dishes because the previous study concluded that it could get better recruitment rates if did not bubble air into the vessels (Golbuu and Richmond 2007).

For all of the settlement experiments, the number of larvae that had metamorphosed on each substratum was assessed after $24 \mathrm{~h}$ under the dissecting microscope following the criteria of Heyward and Negri (1999). Only larvae that both settled and metamorphosed were recorded in each replicate dish. Larvae could settle and metamorphose on three potential substrata in each dish within the no-choice experiments: the top surface of the chip, the side of the chip, and the dish itself. In the paired-choice experiments, there were five possible settlement substrata for settlement and metamorphosis: the top surface of each chip (2), the side of each chip (2), and the dish (1).

To test the larvae post-settlement survival after the indoor settlement experiment, all the unattached larvae were discarded, and the substrata as well as the petri dishes with metamorphosed coral spat were maintained in aquaria $(3.2 \mathrm{~m} \times 1.8 \mathrm{~m} \times 0.8 \mathrm{~m})$ with flow-through seawater for 14 days. The mean seawater temperature was $27.5^{\circ} \mathrm{C}$, salinity was $33.0 \mathrm{psu}$, and the average light intensity at the bottom of aquaria was $185.0 \mu \mathrm{mol}$ photons $\mathrm{m}^{-2} \mathrm{~s}^{-1}$, which was close to the irradiance at the coral larval sampling site.

\section{Data analyses}

Since the experimental dishes were organized in a randomized block design and there was no $100 \%$ larval metamorphosis, the number of larvae available to settle on any substratum type was not limited. This allowed our data to be analyzed by a randomized block design ANOVA (oneway ANOVA), in which each replicate was a block. The proportion of larval metamorphosis rates was not normally distributed, so they were rank transformed, and then they were compared among treatments. Significant groups were determined by the Tukey's HSD post hoc test if there was a significant difference of larval metamorphosis among the substrata. Statistical calculations were carried out by SPSS software v20.0 (IBM Inc.).

\section{Results}

Larvae of A. millepora had significant different rate of total metamorphosis in response to each treatment $(p<0.001)$. Mean larval metamorphosis varied greatly ranging from 2 to $73 \%$ across the treatments. Larval metamorphosis was higher in the treatments with the presence of living or dead CCA chips than in the other treatments, either in the nochoice experiment or in the paired-choice experiment. Additionally, these experiments showed a wide range of number of larvae settled among replicates in each treatment (varied from 0 to 17), but the overall rates of metamorphosis were higher in choice experiments than that observed in no-choice experiments. The control (petri dish) and the glass treatment both had the lowest larvae settlement number (replicates varied from 0 to 1); the living and dead CCA treatment had the highest larvae settlement number (replicates varied from 11 to 17), followed by dead CCA treatment (replicates varied from 8 to 17) and living CCA treatment (replicates varied from 12 to 15 ).

In the no-choice experiments, larvae of A. millepora had significantly different rate of total metamorphosis between the CCA chips and other treatments (Fig. 1A, $p<0.001$ ). Average metamorphosis was variable in each treatment with a range between 2 and $71 \%$, while once larvae detect the inducers of CCA chips they prefer to settle on the adjacent petri dish.

The control (petri dish, Fig. 1B) and the glass treatment (Fig. 1F) both had the lowest metamorphosis (replicates varied from 0 to 5\%); the dead CCA treatment (Fig. 1D) had the highest metamorphosis (replicates varied from 40 to $90 \%$ ), followed by living CCA treatment (replicates varied from 60 to $75 \%$, Fig. 1C) and tile treatment (replicates varied from 0 to $35 \%$, Fig. 1E).

Only the treatments with CCA chips induced more metamorphosis than all the other treatments (which were not different from each other). In the CCA treatments, settlement and metamorphosis on the side of each chip (living 19\%, dead 2\%) was higher than that on the surface of each chip (living 7\%, dead 1\%).

When compared by the position of settlement onto the substrata type, larvae settlement and metamorphosis on the surface of the dish in CCA treatments was greater than the other treatments. In the living CCA treatment, there was significant difference between substrata (Fig. 1C, $p=0.013$ ), and more larval metamorphosis on the surface of the dish and side of the living CCA chip than that on the living CCA chip surface. In the dead CCA treatment, there was also significant difference between substrata (Fig. 1D, $p<0.001$ ), and more larval metamorphosis on the surface of dish than that on the side or surface of the dead CCA chip.

In the paired-choice experiments between living CCA chips and dead CCA chips, the larvae of A. millepora had different metamorphosis rate onto the five substratum types (Fig. 2A, $p<0.001$ ). Living CCA induced higher rate of larval metamorphosis on both the side of living CCA chip and the surface of dish than that on any of the other substrata. When the choice between living CCA chips and tile chips, there was also a difference between substrata (Fig. 2B, 

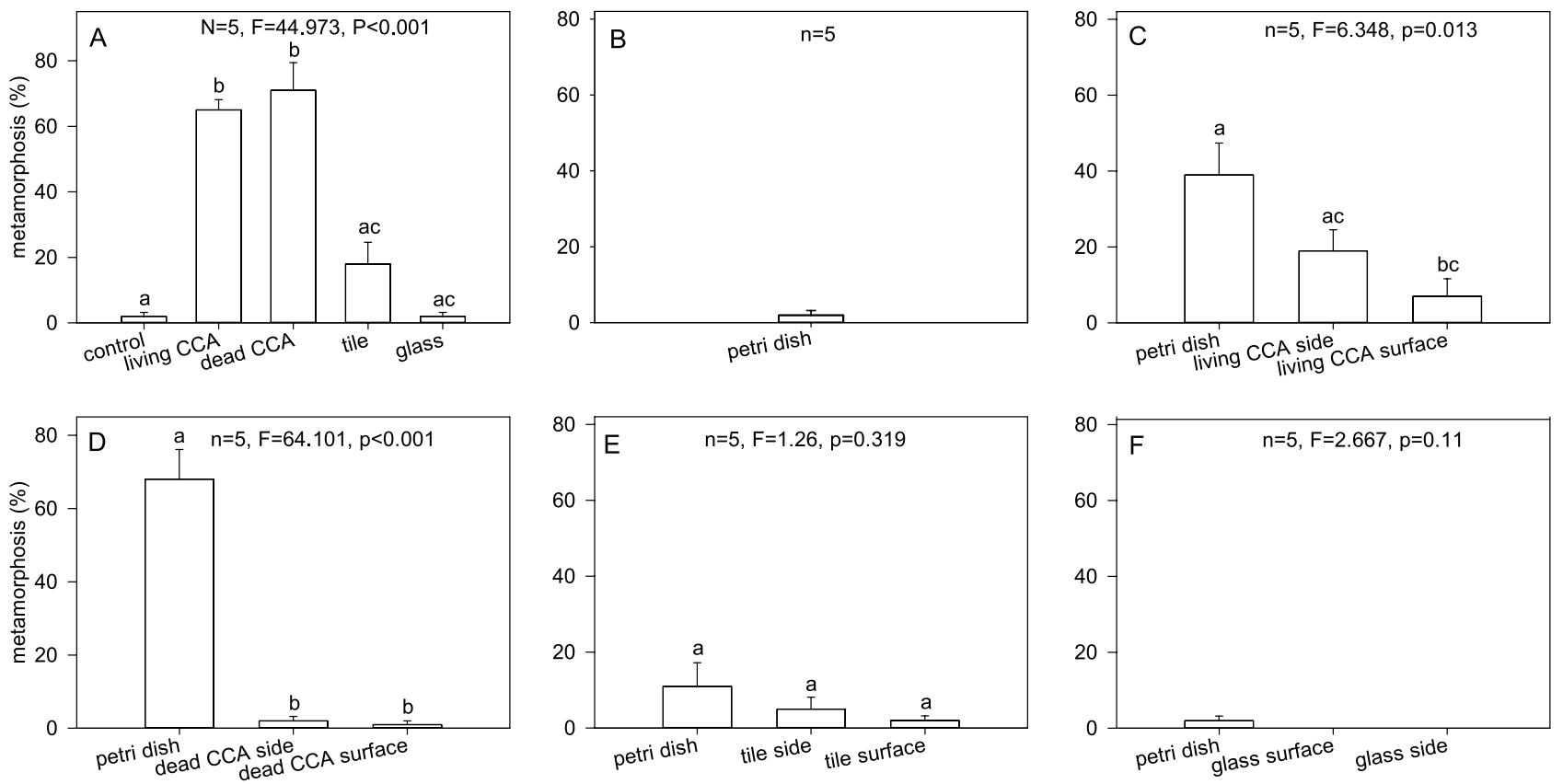

Fig. 1 A. millepora larvae metamorphosis in no-choice experiment. A. The total larvae settle and metamorphose. B. The petri dish treatments serve as the control. C. Larvae settle and metamorphose on three substrata in the living CCA treatments. D. Larvae settle and metamorphose on three substrata in the dead CCA treatments. E. Lar-

$p<0.001$ ), and living CCA induced more larval metamorphosis on the surface of dish and living CCA chip and side of living CCA chip than that on the other two substrata. When the choice between living CCA chips and glass chips, there was also a difference between substrata (Fig. 2C, $p<0.001)$. Living CCA induced more larval metamorphosis on the surface of dish and the surface or side of living CCA chip than that on the surface or side of glass chip, but larvae metamorphosis on the surface of living CCA chip did not differ from the surface or side of glass chip. In the dead CCA and tile treatments, the surface of dish, dead CCA chip, and tile chip and the side of dead CCA chip had more larvae metamorphosis than on the side of tile chip (Fig. 2D, $p<0.001)$. Both the surface and the side of dead CCA chip had the similar rate of larval metamorphosis $(3.2,3.6 \%)$. There was no difference in the amount of larval metamorphosis on the different substrata except for dish (Fig. 2E, $p<0.001)$ in dead CCA and glass treatments. The tile and glass treatments showed no difference of larval metamorphosis among settlement substrata (Fig. $2 \mathrm{~F}, p=0.098$ ), and the mean metamorphosis rate on the five different substrata was $7 \%$ or less.

The mean survival of new recruits of A. millepora was approximately $68 \%$ on all the settlement substrata after 2 weeks, but no coral spat survived on the control (petri dish), tile and glass treatment (Fig. 3). There were statistical differences between the larvae survival of dead CCA and vae settle and metamorphose on three substrata in the tile treatments. F. Larvae settle and metamorphose on three substrata in the glass treatments. Bar represent the mean \% metamorphosis and SE. Shared letters above the bars indicate treatments are not statistically different as determined by the Tukey's HSD post hoc test

glass chips treatment and the others where CCA was present (Tukey's HSD post hoc test, $p<0.05$ ).

\section{Discussion}

This study aimed to test the settlement specificity of a threatened coral A. millepora in Sanya reefs by measuring the larval metamorphosis preferences and post-settlement survival in response to CCA species $H$. reinboldii and other substrata. The results showed higher settlement and post-settlement survival rate of A. millepora in the presence of CCA than the other substrata, and regardless if the CCA tissue is living or not. These results reflect the inducing cues involved in the CCA could facilitate coral larval settlement. This is especially important for the coral recruitment processes and reconstructing the coral population and community structure in the Sanya degrading reefs.

Some species of CCA inducing the settlement of reefbuilding coral larvae had been proposed that the induction was driven by the cues from CCA surface-associated biofilms (Webster et al. 2004, Ritson-Williams et al. 2016, Siboni et al. 2020) or specific compounds produced by CCA (Harrington et al. 2004, Sneed et al. 2014, Tebben et al. 2015), and or both (Gomez-Lemos et al. 2018). Other research revealed that CCA-chemical compounds (Sneed et al. 2014, Tebben et al. 2015) and surface complexity 

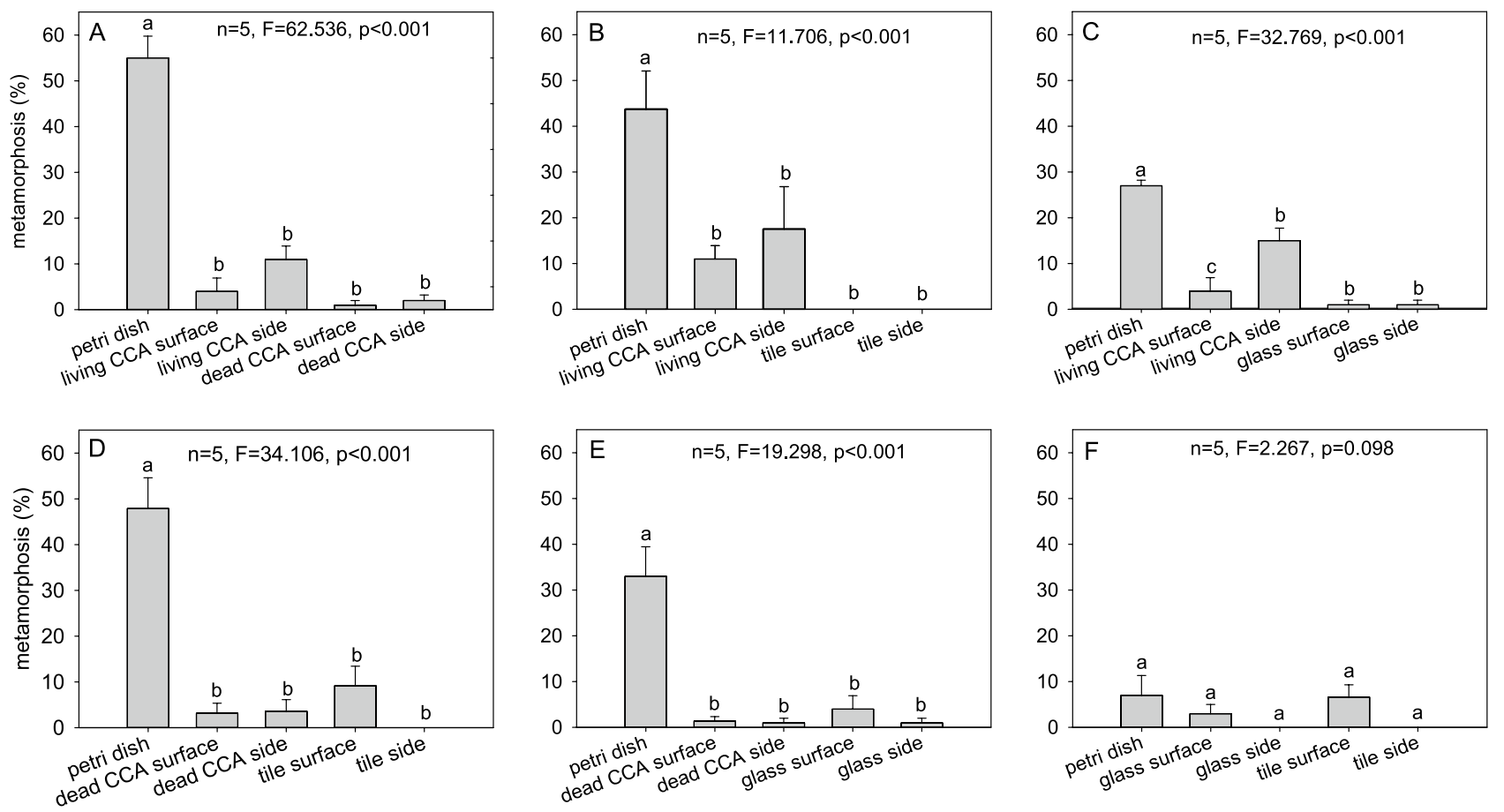

Fig. 2 A. millepora larval choice experiment. A. Larval metamorphosis on different substrata given a choice between the CCA species chips with living and dead tissue. B. Larval metamorphosis given a choice between the CCA species with living tissue and tiles chips. C. Larval metamorphosis given a choice between the CCA species with living tissue and glass chips. D. Larval metamorphosis given a choice between the CCA species with dead tissue and tiles chips. E.

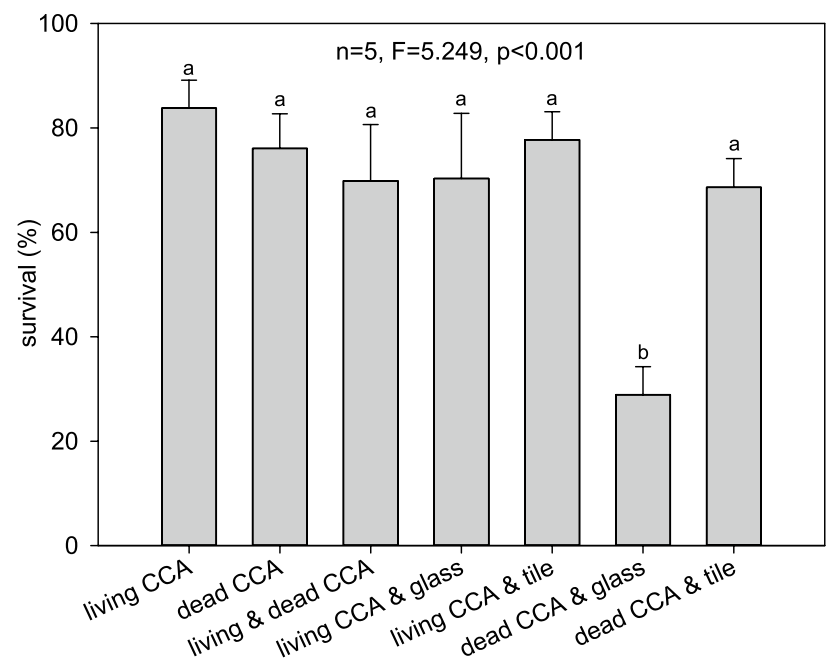

Fig. 3 Post settlement survival of A. millepora larvae. Substrata with newly metamorphosed coral spat were maintained in aquaria with flow-through seawater for two weeks. The error bars are $\pm \mathrm{SE}$ for the mean $\%$ survival. Shared letters above the bars indicate treatments are not different as determined by the Tukey's HSD post hoc test
Larval metamorphosis given a choice between the CCA species with dead tissue and glass chips. F. Larval metamorphosis given a choice between the tiles and glass chips. The error bars are \pm SE for the mean $\%$ metamorphosis. Shared letters above the bars indicate treatments are not different as determined by the Tukey's HSD post hoc test

(thallus surface morphological characteristic) (Whalan et al. 2015, Laju et al. 2019), and color (Mason et al. 2011; Foster and Gilmour 2016) could serve as inducers of coral larvae settlement. Additionally, study also indicated that not the bacterial biofilms on CCA but the CCA cell wall-associated compounds did initiate realistic settlement responses to coral larvae (Tebben et al. 2015). These findings need not be mutually exclusive, for we did not focus on the effect of them in this experiment, but our results suggest that the physical effects of CCA contributed to the coral settlement.

Furthermore, larvae need direct contact with the CCA thallus surface to sense the inducing cues to settle down. In our study, there more larvae settled on the surface or side of CCA chips than the other substrata (Fig. 1, Fig. 2), indicating that coral larvae recognized the inducing cues of the CCA for settlement. Moreover, photosynthetic products of CCA are not only released to the seawater as dissolved organic matter but are also stored in their thallus. The CCA organic matter has been shown to serve as a direct or indirect inducer of larvae settlement (Johnson and Sutton 1994, Tebben et al. 2015, Gomez-Lemos et al. 2018). In the no-choice treatment or the paired-choice treatment, the proportion of larvae settled on the surface or side of CCA chips was high 
confirming the results that CCA organic matter could probably serve as an inducing cue, although it cannot be teased apart from our experiments. There were more larvae settled on the plastic petri dishes in the treatment when CCA present, indicating coral larvae might sense the inducting cue of CCA dissolved organic matter in seawater (Gomez-Lemos et al. 2018) or that cues were detected at the CCA surface but the larvae might prefer to subsequently attach on a more inert substrate such as the dish (Tebben et al. 2015).

Research suggested that specific physical cues (surface complexity) could also play an important role in coral larval settlement. Laboratory-based study indicated CCA surface microtopography alone (without chemical cues) induced higher larval settlement to the surface holes closely matched the larval size (Whalan et al. 2015). The CCA species $H$. reinboldii tested here had a surface similar to Phymatolithon-type, and this type of surface had flat cell surfaces with a minute central hole (Lei et al. 2020), that was the tetrasporangial conceptacle slightly protruding and open to the algae surface $(40-100 \mu \mathrm{m})$. According to the high larval settlement rate on the CCA thallus surface, we concluded the larvae of A. millepora might prefer this CCA surface microtopography. Study also found the dead coral substrate might attract coral larvae that are morphologically similar (Norstrom et al. 2007), and a field assessment found coral recruits (Turbinaria sp., Cyphastrea sp., and Favia sp.) on bivalve shells (Modiolus philippinarum) (Laju et al. 2019). These results suggest that substrate with a rough surface is likely to be a good inducer for the settlement of coral larvae.

Suitable settlement substrata and post-settlement survival are the vital steps in the life cycle of reef corals, and thus is a key bottleneck for the recovery of the damaged coral populations. In our experiment, high rates of settlement related to high rates of post-settlement survival, which was consistent with the results found by (Price 2010, Ritson-Williams et al. 2010, Price et al. 2019). Especially, each treatment had high larvae settlement and metamorphosis and post-settlement survival when CCA was present regardless of the algae tissue is living or not.

In conclusion, our study has provided an experimental evidence of larval settlement cues from the CCA species $H$. reinboldii. Our results provided a new sight on the roles of CCA as inducers (e.g., the physical feature) of coral larval settlement. CCA was a strong driver of settlement; however, whether the CCA tissue was alive or not would influence where the larvae settled. However, we do not discount the possibility that facilitating CCA species host a specific biofilm community and the important inducing role of the chemical organic products of CCA, for their specific pathways as an inducer to the coral larval settlement had not been tested in our experiment. As a fundamental process for the recovery of degraded coral reef habitats, future studies should focus on the in situ presentation and quantification of larval responses to CCA inherent cues. This will further improve our understanding of the potential of CCA in increasing the abundance of corals in Sanya reefs and other reef ecosystems.

Supplementary Information The online version contains supplementary material available at https://doi.org/10.1007/s00227-021-03943-7.

Acknowledgments This research was supported by the National Natural Science Foundation of China (41306144, 41876192, 41976120), Guangdong Basic and Applied Basic Research Foundation (2019A1515011532), Key Research and Development Project of Hainan Province, China (ZDYF2020200), Science and Technology Planning Project of Guangdong Province, China (2020B1212060058), Innovation Academy of South China Sea Ecology and Environmental Engineering, Chinese Academy of Sciences (ISEE2018PY01). We would like to thank the staff of Tropical Marine Biological Research Station in Hainan, CAS, for their logistical and administrative support. Our thanks and appreciation to the anonymous reviewers and the associate editor whose thoughtful comments improved this manuscript substantially.

Author contributions This study was designed by XML, the experiment was carried out by XML and LJ, the data analysis was conducted by XML, the paper was written and revised by XML, LJ, YL, YYZ, YFS, GWZ, JSL and HH.

Data Availability Data pertaining to this work are available from the corresponding author on reasonable request.

\section{Declarations}

Conflicts of interest The authors declare that they have no conflict of interest.

Ethical standards All necessary permits to access field sites and conduct the research described in this paper were obtained from the Tropical Marine Biological Research Station in Hainan, Chinese Academy of Sciences (Permit No: 20160327SY, dated Dec. 30th, 2016).

Open Access This article is licensed under a Creative Commons Attribution 4.0 International License, which permits use, sharing, adaptation, distribution and reproduction in any medium or format, as long as you give appropriate credit to the original author(s) and the source, provide a link to the Creative Commons licence, and indicate if changes were made. The images or other third party material in this article are included in the article's Creative Commons licence, unless indicated otherwise in a credit line to the material. If material is not included in the article's Creative Commons licence and your intended use is not permitted by statutory regulation or exceeds the permitted use, you will need to obtain permission directly from the copyright holder. To view a copy of this licence, visit http://creativecommons.org/licenses/by/4.0/.

\section{References}

Fiege D, Neumann V, Li JH (1994) Observations on coral-reefs of Hainan-Island, South China Sea. Mar Pollut Bull 29:84-89. https://doi.org/10.1016/0025-326x(94)90430-8 
Foster T, Gilmour JP (2016) Seeing red: Coral larvae are attracted to healthy-looking reefs. Mar Ecol Prog Ser 559:65-71. https://doi. org/10.3354/meps 11902

Golbuu Y, Richmond RH (2007) Substratum preferences in planula larvae of two species of scleractinian corals, Goniastrea retiformis and Stylaraea punctata. Mar Biol 152:639-644. https://doi.org/ 10.1007/s00227-007-0717-x

Gomez-Lemos LA, Doropoulos C, Bayraktarov E, Diaz-Pulido G (2018) Coralline algal metabolites induce settlement and mediate the inductive effect of epiphytic microbes on coral larvae. Sci Rep 8:17557. https://doi.org/10.1038/s41598-018-35206-9

Harrington L, Fabricius K, De'Ath G, Negri A (2004) Recognition and selection of settlement substrata determine post-settlement survival in corals. Ecology 85:3428-3437. https://doi.org/10.1890/04-0298

Heyward A, Negri A (1999) Natural inducers for coral larval metamorphosis. Coral Reefs 18:273-279. https://doi.org/10.1007/ s003380050193

Hutchings PA, Wu BL (1987) Coral reefs of Hainan Island, South China Sea. Mar Pollut Bull 18:25-26. https://doi.org/10.1016/ 0025-326x(87)90652-7

Johnson CR, Sutton DC (1994) Bacteria on the surface of crustose coralline algae induce cetamorphosis of the crown-of-shorns starfish Acanthaster planci. Mar Biol 120:305-310. https://doi.org/ 10.1007/Bf00349692

Kayal M, Lenihan HS, Brooks AJ, Holbrook SJ, Schmitt RJ, Kendall BE (2018) Predicting coral community recovery using multispecies population dynamics models. Ecol Lett 21:1790-1799. https://doi.org/10.1111/ele.13153

Knowlton N (2001) The future of coral reefs. P Natl Acad Sci USA 98:5419-5425. https://doi.org/10.1073/pnas.091092998

Laju RL, Mathews G, Raj KD, Edward JKP (2019) Corals recruit onto live and dead shells of the bivalve Modiolus philippinarum. Bull Mar Sci 95:197-198. https://doi.org/10.5343/bms.2018.0089

Lei XM, Huang H, Lian JS, Zhou GW, Jiang L (2018) Community structure of coralline algae and its relationship with environment in Sanya reefs, China. Aquat Ecosyst Health 21:19-29. https://doi. org/10.1080/14634988.2018.1432954

Lei X, Jiang L, Sun Y, Zhang Y, Zhou G, Yang J, Lian J, Huang H (2020) Six thallus surface types of coralline algae with descriptions of two new records of Amphiroa beauvoisii and Neogoniolithon setchellii in Sanya reef, China. J Mar Sci 2:23-30. https:// doi.org/10.30564/jms.v2i2.1822

Li XB, Huang H, Lian JS, Yang JH, Ye C, Chen YQ, Huang LM (2013) Coral community changes in response to a high sedimentation event: a case study in southern Hainan Island. Chin Sci Bull 58:1028-1037. https://doi.org/10.1007/s11434-012-5601-5

Lian JS, Huang H, Huang LM, Wang DR (2010) Coral reef and its biodiversity of Sanya. Marine Press, Beijing

Mason B, Beard M, Miller MW (2011) Coral larvae settle at a higher frequency on red surfaces. Coral Reefs 30:667-676. https://doi. org/10.1007/s00338-011-0739-1

Norstrom AV, Lokrantz J, Nystrom M, Yap HT (2007) Influence of dead coral substrate morphology on patterns of juvenile coral distribution. Mar Biol 150:1145-1152. https://doi.org/10.1007/ s00227-006-0458-2

Nozawa Y, Harrison PL (2008) Temporal patterns of larval settlement and survivorship of two broadcast-spawning acroporid corals. Mar Biol 155:347-351. https://doi.org/10.1007/s00227-008-1034-8

Pearson RG (1981) Recovery and recolonization of coral reefs. Mar Ecol Prog Ser 4:105-122. https://doi.org/10.3354/meps004105

Polidoro B, Carpenter K (2013) Dynamics of coral reef recovery. Science 340:34-35. https://doi.org/10.1126/science.1236833

Price N (2010) Habitat selection, facilitation, and biotic settlement cues affect distribution and performance of coral recruits in French Polynesia. Oecologia 163:747-758. https://doi.org/10.1007/ s00442-010-1578-4
Price NN, Muko S, Legendre L, Steneck R, van Oppen MJH, Albright R, Ang P, Carpenter RC, Chui APY, Fan TY, Gates RD, Harii S, Kitano H, Kurihara H, Mitarai S, Padilla-Gamino JL, Sakai K, Suzuki G, Edmunds PJ (2019) Global biogeography of coral recruitment: tropical decline and subtropical increase. Mar Ecol Prog Ser 621:1-17. https://doi.org/10.3354/meps12980

Randall CJ, Negri AP, Quigley KM, Foster T, Ricardo GF, Webster NS, Bay LK, Harrison PL, Babcock RC, Heyward AJ (2020) Sexual production of corals for reef restoration in the Anthropocene. Mar Ecol Prog Ser 635:203-232. https://doi.org/10.3354/meps13206

Ritson-Williams R, Paul VJ, Arnold SN, Steneck RS (2010) Larval settlement preferences and post-settlement survival of the threatened Caribbean corals Acropora palmata and A. cervicornis. Coral Reefs 29:71-81. https://doi.org/10.1007/s00338-009-0555-Z

Ritson-Williams R, Arnold SN, Paul VJ (2016) Patterns of larval settlement preferences and post-settlement survival for seven Caribbean corals. Mar Ecol Prog Ser 548:127-138. https://doi.org/10. 3354/meps 11688

Sato Y, Bell SC, Nichols C, Fry K, Menendez P, Bourne DG (2018) Early-phase dynamics in coral recovery following cyclone disturbance on the inshore great barrier reef, Australia. Coral Reefs 37:431-443. https://doi.org/10.1007/s00338-018-1668-z

Siboni N, Abrego D, Puill-Stephan E, King WL, Bourne DG, Raina J-B, Seymour JR, Harder T (2020) Crustose coralline algae that promote coral larval settlement harbor distinct surface bacterial communities. Coral Reefs 39:1703-1713. https://doi.org/10.1007/ s00338-020-01997-5

Sneed JM, Sharp KH, Ritchie KB, Paul VJ (2014) The chemical cue tetrabromopyrrole from a biofilm bacterium induces settlement of multiple Caribbean corals. Proc R Soc B 281:20133086. https:// doi.org/10.1098/rspb.2013.3086

Sun YF, Lei XM, Lian JS, Yang JH, Wu YY, Huang H (2018) Ecosystem status and health assessment of Sanya Coral Reef National Nature Reserve. Biodiv Sci. 26(3):258-265. https://doi.org/10. 17520/biods.2017312

Suzuki G, Arakaki S, Hayashibara T (2011) Rapid in situ settlement following spawning by Acropora corals at Ishigaki, Southern Japan. Mar Ecol Prog Ser 421:131-138. https://doi.org/10.3354/ meps08896

Tebben J, Motti CA, Siboni N, Tapiolas DM, Negri AP, Schupp PJ, Kitamura M, Hatta M, Steinberg PD, Harder T (2015) Chemical mediation of coral larval settlement by crustose coralline algae. Sci Rep 5:10803. https://doi.org/10.1038/srep10803

Tran C, Hadfield MG (2013) Localization of sensory mechanisms utilized by coral planulae to detect settlement cues. Invertebr Biol 132:195-206. https://doi.org/10.1111/ivb.12025

Webster NS, Smith LD, Heyward AJ, Watts JEM, Webb RI, Blackall LL, Negri AP (2004) Metamorphosis of a scleractinian coral in response to microbial biofilms. Appl Environ Microbiol 70:12131221. https://doi.org/10.1128/Aem.70.2.1213-1221.2004

Whalan S, Wahab MA, Sprungala S, Poole AJ, de Nys R (2015) Larval settlement: the role of surface topography for sessile coral reef invertebrates. PLoS One. https://doi.org/10.1371/journal.pone. 0117675

Yu DP, Zhou RL (1996) Current situation and dynamics of species diversity in hermatypic coral community on Luhuitou fringing reef. Acta Ecol Sin 16:559-564. https://doi.org/10.1007/BF02951625

Zhang SZ, Huang H, Zhang YY, Zhou GW, Jiang L, Chen B (2016) Histological analyses of the gonad for Acropora millepora and Galaxea fascicularis from Sanya Luhuitou of Hainan Island. Ecol Sci 35:41-46. https://doi.org/10.14108/j.cnki.1008-8873.2016.01.006

Publisher's Note Springer Nature remains neutral with regard to jurisdictional claims in published maps and institutional affiliations. 